\title{
IMPACT OF ANTENATAL CARE ON MATERNAL MORBIDITY IN THREE MILITARY HOSPITALS OF PUNJAB, PAKISTAN
}

\author{
Rizwana Akbar, Naila Azam*, Fatima Ali Raza Mughal*, Ahmed Tariq**, Maira Wajahat*** \\ Armed Forces Post Graduate Medical Institute/National University of Medical Sciences (NUMS) Rawalpindi Pakistan, *Foundation University Medical College, \\ Islamabad Pakistan, **Army Medical College/National University of Medical Sciences (NUMS) Rawalpindi Pakistan, ***Pak Emirates Military Hospital/National \\ University of Medical Sciences (NUMS) Rawalpindi Pakistan
}

\section{ABSTRACT}

Objective: To determine the impact of antenatal care on maternal morbidity.

Study Design: Comparative cross-sectional study.

Place and Duration of Study: Obstetric Departments of three military hospitals in Northern Punjab cities of Rawalpindi, Jehlum and Mangla, from Jan to Mar 2019.

Methodology: Data of all mothers who gave live births in the selected military hospitals were collected. These mothers were classified as booked and unbooked on the basis of number of antenatal care visits. Maternal morbidities and complications of pregnancy were recorded. The data were analyzed using Statistical Packages for Social Science (SPSS) version 20.

Results: In our study, 254 (8.8\%) of mothers were unbooked, 2273 (78.8\%) were partially booked and $358(12.4 \%)$ were booked. $894(31 \%)$ mothers did not have any co-morbidity while 1991 (69\%) mother had co-morbidity. Out of $749(27.5 \%)$ mothers had anaemia, $869(30.1 \%)$ had hypertension, $141(30.1 \%)$ had diabetes mellitus, $24(0.8 \%)$ cardiac disease, $39(1.4 \%)$ had tuberculosis, $9(0.3 \%)$ had liver disease $13(0.5 \%)$ had kidney disease, $69(2.4 \%)$ had allergies while $33(1.1 \%)$ had other diseases. These complications were significantly greater in unbooked patients as compared to booked patients $(p<0.001)$ Out of total 2885 mothers who gave live births in three military hospitals, only one $(0.034 \%)$ mother died (who was unbooked) in Jhelum Hospital. Its Maternal Mortality Ratio (MMR) was 34.66 per 100,000 live births.

Conclusion: In our study population anemia, hypertension and diabetes were the most common comorbidities in expecting mothers. Unbooked mothers had more morbidities and complications of pregnancy than booked mothers. Furthermore, we found antenatal care to be beneficial in the prevention of these comorbidities and complications.

Keywords: Ante-natal care, Complications of pregnancy, Maternal morbidity.

How to Cite This Article: Akbar R, Azam N, Mughal FAR, Tariq A, Wajahat M. Impact of Antenatal Care on Maternal Morbidity in Three Military Hospitals of Punjab, Pakistan. Pak Armed Forces Med J 2021; 71(5): 1682-1686. doi: https://doi.org/10.51253/pafmj.v71i5.5157

This is an Open Access article distributed under the terms of the Creative Commons Attribution License (https://creativecommons.org/licenses/by-nc/4.0/), which permits unrestricted use, distribution, and reproduction in any medium, provided the original work is properly cited.

\section{INTRODUCTION}

Health care services for pregnant women are important for the survival and wellbeing of both mother and infant. According to the Pakistan Demographic Health Survey, ${ }^{1}$ (PDHS) 2017-18, Pakistan has lagged in achieving the health-related Millennium Development Goals, ${ }^{2}$ (MDGs), particularly Goal no 5 which is "improve maternal health". In September 2015, the Sustainable Development Goals (SDGs) were set by the United Nations. The goal number 3 was to ensure healthy lives and SDG target number 3.1 was to reduce global maternal mortality ratio to 70 per 100000 live births. $^{3}$

Maternal morbidity is a pressing concern among Pakistani mothers. ${ }^{4,5}$ According to the PDHS, ${ }^{1}$ only $86 \%$ of women who gave live birth in the 5 years preceding the survey received antenatal care (ANC) from

Correspondence: Dr Rizwana Akbar, House No. NE 289, Jinnah Colony, Tipu Road, Rawalpindi Pakistan

Received: 24 Aug 2020; revision received: 30 Dec 2020; accepted: 31 Dec 2020 a skilled provider at least once for their last birth. About half of the consultations were by qualified doctors. ${ }^{6}$ Eighty-five percent of women were satisfied with the services provided. In our country both socio-economic factors and health information sources are associated with women's use of ANC.7,8

According to UNICEF's Report (Press Release, New York, 20 $0^{\text {th }}$ February 2018), Pakistan had the world's highest number of neonatal mortality rate of 1 death in 22 live births (45.5 per 1000 live births). Since three-fourth of neonatal deaths occur in the first week of life, they are attributable to maternal causes as well, which are preventable. The main causes of maternal morbidity were anaemia, hypertension, and diabetes mellitus, and the main complications of pregnancy were gestational diabetes mellitus, fetal distress, preterm labour, haemorrhage, pre eclampsia, and eclampsia. These morbidities during pregnancy can be detected and complications during pregnancy and delivery can be prevented by quality antenatal care with appropriate number of visits appropriately distributed 
during pregnancy. This in turn can reduce maternal morbidity during pregnancy and improve outcomes of pregnancy and maternal health. 9,10

World Health Organization (WHO) in 2002 in the Focused Approach on Antenatal Care (FANC) recommended 4 antenatal care (ANC) visits appropriately distributed throughout pregnancy. On $7^{\text {th }}$ November 2016, WHO later recommended at least 8 contacts in antenatal care programs to reduce maternal morbidity and mortality and improve neonatal and maternal health. Due to limited hospital-based ANC data available from the region of Punjab, we designed this study to determine the association between antenatal care and its impact on maternal morbidity in three military hospitals.

\section{METHODOLOGY}

It was a comparative cross-sectional study. Data were collected from the obstetric departments of three hospitals in Northern Punjab cities of Rawalpindi, Jehlum and Mangla from Jan to March 2019.

Inclusion Criteria: The study population included mothers who delivered in the three military hospitals.

Exclusion Criteria: Non-consenting females were excluded.

This study was conducted after approval from the Ethical Review Board of Armed Forces Post Graduate Medical Institute (Ltr no.: 192-AAA-ERC-AFPGMI). Permission was sought from the administrators of the respective hospitals for the collection of data. Coding was used to guarantee the confidentiality of data/ information. No monetary compensation was given to the study participants.

In this study, we have considered mothers with 4 or more visits as" booked" for antenatal care. If a mother had 3 antenatal visits, she was considered as "par- tially booked". If a mother had less than 2 visits or no antenatal care visits, she was considered "unbooked". A self-designed structured, data collection tool was used for the collection of data against preset criteria for cases of neonatal mortality and morbidity and their mothers. It was prepared by modifying the data collection tool ${ }^{11}$ used in a study at Health Services Academy, Islamabad with the author's permission.

Data were analyzed using Statistical Packages for Social Science (SPSS) version 20. The responses of the questionnaires were coded and scored to facilitate the entry of data. Quantitative variables were reported as Mean \pm SD (Standard Deviation) while categorical variables were reported as frequencies and percentages. For inferential statistics, chi-square test was applied to find an association between qualitative variables (e.g. quality of antenatal services and maternal morbidity). The confidence interval was taken as $95 \%$, margin of error $5 \%$ and $p$-value $\leq 0.05$ was considered statistically significant.

\section{RESULTS}

A total of 2885 mothers, who gave live births in three hospitals were studied. Out of these, $2304(80 \%)$ mothers were admitted in hospital in Rawalpindi (being largest), 343 (12\%) were admitted in Jhelum and $238(8 \%)$ were admitted in Mangla hospitals respectively.

On inquiry $254(8.8 \%)$ mothers were unbooked, $2273(78.8 \%)$ were partially booked and $358(12.4 \%)$ were booked. The duration of pregnancy of $267(9.3 \%)$ mothers were pre-term, 2612 (90.5\%) mothers were full-term and $6(0.2 \%)$ mothers were post-term. Out of $966(33.50 \%)$ were primigravida, $539(18.70 \%)$ were second gravida $1380(47.80 \%)$ were third or more gravida (Table-I).

Table-I: Descriptive statistics of the study participants.

\begin{tabular}{|c|c|c|c|c|}
\hline \multicolumn{2}{|l|}{ Parameters } & Rawalpindi & Jhelum & Mangla \\
\hline \multicolumn{2}{|c|}{ Total the study participants $\mathrm{n}(\%)$} & $2304(80 \%)$ & $343(12 \%)$ & $238(8 \%)$ \\
\hline \multirow{3}{*}{$\begin{array}{l}\text { Booking Status } \\
\mathrm{n}(\%)\end{array}$} & Unbooked & $205(8.9 \%)$ & $41(12 \%)$ & $4(1.8 \%)$ \\
\hline & Partially booked & $2087(90.6)$ & $94(27.5 \%)$ & $45(18.7 \%)$ \\
\hline & Booked & $12(0.5 \%)$ & $208(60.5 \%)$ & $189(79.5 \%)$ \\
\hline \multicolumn{2}{|l|}{ Age (years) } & $28.16 \pm 4.59$ & $28.05 \pm 4.47$ & $29.45 \pm 3.53$ \\
\hline \multirow{2}{*}{ Income Status (\%) } & Less than 25000 & 1 & 35 & 1 \\
\hline & More than 25000 & 99 & 65 & 99 \\
\hline \multirow{3}{*}{$\begin{array}{l}\text { Duration of } \\
\text { Pregnancy (\%) }\end{array}$} & Pre-term & 10.2 & 6.4 & 4.3 \\
\hline & Full Term & 89.7 & 93.0 & 95.7 \\
\hline & Post-Term & 0.3 & 0.6 & 0.0 \\
\hline \multirow{3}{*}{$\begin{array}{l}\text { Gravidity Status } \\
\mathrm{n}(\%)\end{array}$} & Primi & $829(36 \%)$ & $103(30 \%)$ & $33(14 \%)$ \\
\hline & Second & $414(18 \%)$ & $72(21 \%)$ & $52(22 \%)$ \\
\hline & Third or more & $2302(46 \%)$ & $168(49 \%)$ & $153(64 \%)$ \\
\hline
\end{tabular}


Out of $894(31 \%)$ mothers did not have any comorbidity while 1991 (69\%) mothers had co-morbidity. Out of $749(27.5 \%)$ mothers had anaemia, 869 (30.1\%) had hypertension, 141 (30.1\%) had diabetes mellitus, $24(0.8 \%)$ cardiac disease, $39(1.4 \%)$ had tuberculosis, 9 $(0.3 \%)$ had liver disease $13(0.5 \%)$ had kidney disease, $69(2.4 \%)$ had allergies while $33(1.1 \%)$ had other diseases (Figure-1).

About 2357 (81.7\%) mothers did not have any complications of pregnancy while $528(18.3 \%)$ had a complication during pregnancy. Out of $1.60 \%$ mothers had pre-eclamptic toxaemia, $(1.5 \%)$ eclampsia, $(6.20 \%)$ gestational diabetes mellitus, $(0.30 \%)$ had antepartum hermorrhage, $(0.20 \%)$ had postpartum hemorrhage, $(0.20 \%)$ had mal presentation, $(3.20 \%)$ had preterm Labour, $(0.50 \%)$ had post-term labour, $(4.50 \%)$ had fetal distress, $(0.2 \%)$ had preterm rupture of membranes and $0.10 \%$ had Intrauterine growth restriction (IUGR) (Figure-2).

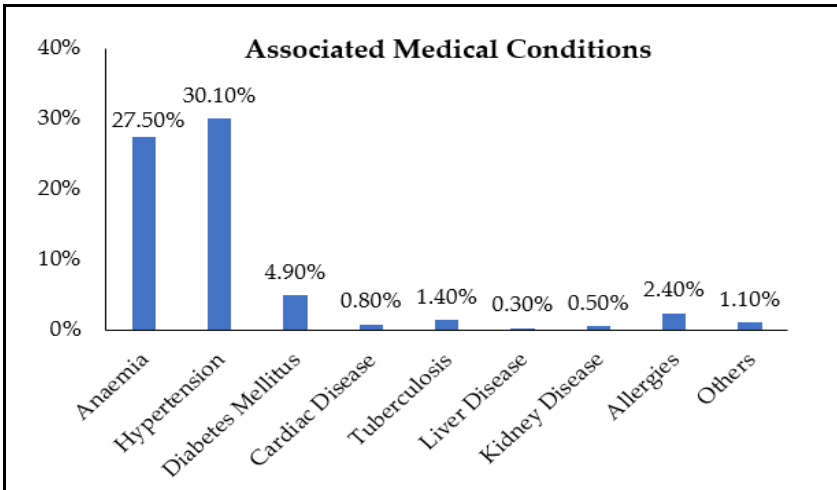

Figure-1: Associated Medical Conditions (Co-Morbidity) of mothers.

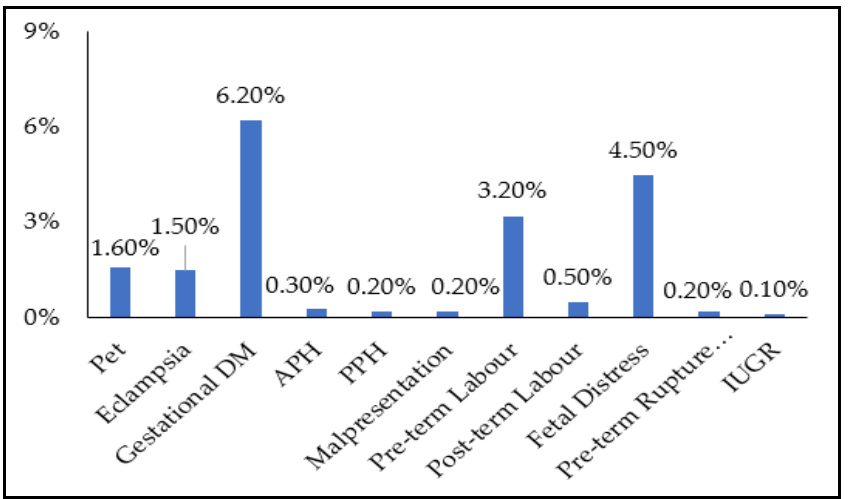

Figure-2: Complications of pregnancy.

Out of 792 mothers who had anaemia, 544 (68.6\%) delivered by Spontaneous vaginal delivery (SVD), 236 $(29.79 \%)$ delivered by caesarian section, 6 had forceps delivery and 6 had vacuum delivery.
Out of 864 mothers who had hypertension, 277 (32\%) delivered by SVD, 16 (1.8\%) had forceps delivery, $11(1.2 \%)$ had vacuum delivery while the rest were delivered by caesarian section.

Out of 139 mothers who had diabetes mellitus, 44 (31.88\%) had SVD, 1 (0.78\%) had forceps delivery, 4 $(2.8 \%)$ had vacuum delivery and the rest had caesarian section.

Statistically, a significant association was found between comorbidity/complications of pregnancy and booked/unbooked Status ( $p=0.001)$ (Table-II).

Out of total 2885 mothers who gave live births in three military hospitals, only one $(0.034 \%)$ mother died (who was unbooked) at hospital in Jhelum. Its Maternal Mortality Ratio (MMR) was 34.66 per 100,000 live births as shown in Table-III.

Table-II: Association between comorbidity/ complications of pregnancy and booked and un-booked status of study participants.

\begin{tabular}{|c|c|c|c|c|}
\hline \multirow{2}{*}{$\begin{array}{l}\text { Co- } \\
\text { Morbidity }\end{array}$} & $\begin{array}{c}\text { Un } \\
\text { Booked }\end{array}$ & $\begin{array}{l}\text { Partially } \\
\text { Booked }\end{array}$ & Booked & $\begin{array}{c}p \text { - } \\
\text { value }\end{array}$ \\
\hline & \multicolumn{3}{|c|}{ Frequency $(\%)$} & \\
\hline Anaemia & $50(20.3)$ & $728(33.1)$ & $12(3.5)$ & \multirow{10}{*}{0.001} \\
\hline Hypertension & $100(40.7)$ & $744(33.8)$ & $17(4.9)$ & \\
\hline \begin{tabular}{l|} 
Diabetes \\
Mellitus \\
\end{tabular} & $16(6.5)$ & $120(5.5)$ & $3(0.9)$ & \\
\hline $\begin{array}{l}\text { Cardiac } \\
\text { Disease }\end{array}$ & $4(1.6)$ & $18(0.8)$ & - & \\
\hline Tuberculosis & $4(1.6)$ & $33(1.5)$ & - & \\
\hline Liver Disease & $2(0.8)$ & $7(0.3)$ & - & \\
\hline \begin{tabular}{l|} 
Kidney \\
Disease
\end{tabular} & - & $13(0.6)$ & - & \\
\hline Allergies & $9(3.7)$ & $60(2.7)$ & - & \\
\hline Others & $2(0.8)$ & $15(0.7)$ & $15(4.3)$ & \\
\hline \begin{tabular}{l|l} 
None & \\
\end{tabular} & $59(24)$ & $462(21)$ & $299(86.4)$ & \\
\hline \multicolumn{4}{|c|}{ Complications of Pregnancy } & \multirow{3}{*}{0.001} \\
\hline \begin{tabular}{l|l} 
Yes & \\
\end{tabular} & $71(24.8)$ & $445(20.2)$ & $15(4.3)$ & \\
\hline \begin{tabular}{|l|l} 
No & \\
\end{tabular} & $185(75.2)$ & $1775(79.8)$ & $331(95.7)$ & \\
\hline \multicolumn{5}{|c|}{ Table-III: Maternal mortality ratio. } \\
\hline & & $\begin{array}{c}\text { Maternal Death } \\
\mathrm{n}(\%)\end{array}$ & \multicolumn{2}{|c|}{$\begin{array}{c}\text { Maternal } \\
\text { Mortality Rate } \\
\end{array}$} \\
\hline \multicolumn{2}{|c|}{$\begin{array}{l}\text { Hospital in } \\
\text { Rawalpindi }\end{array}$} & 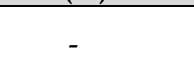 & \multicolumn{2}{|c|}{ 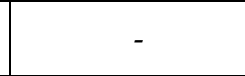 } \\
\hline \multicolumn{2}{|c|}{ Hospital in Mangla } & - & \multicolumn{2}{|c|}{-} \\
\hline \multicolumn{2}{|c|}{ Hospital in Jhelum } & $1(0.034) \%$ & \multicolumn{2}{|c|}{34.66} \\
\hline
\end{tabular}

\section{DISCUSSION}

Antenatal Health care services are essential for maternal and neonatal health and safety during pregnancy. ${ }^{12}$ In the last two decades, Pakistan has been unable to achieve the optimum progress towards utilization of antenatal health care services. ${ }^{13}$ Especially in rural areas, several socio-cultural factors make it diffi- 
cult for women to utilize basic health services. Factors such as education of the mother, income status of the household, autonomy in decision making and reproductive health are highly significant. ${ }^{14,15}$

According to PDHS,1 2017-2018 and Gateway Health Indicators, ${ }^{16}$ of Pakistan. The percentage of women age 15-49 with a live birth in the 5 years before the survey that had 4 or more ANC visits was $51 \%$. In our study, ${ }^{10}$ the percentage of women that had 4 or more ANC visits was $12.4 \%$. However, $78.8 \%$ of women had 3 ANC visits.

In the survey, ${ }^{1} 86 \%$ of women age $15-49$ years with a live birth in the 5 years before the survey received ANC from a skilled provider at least once. In our study, as it was a hospital-based study, all of the women received ANC at least once except for one case.

Out of the mothers' age 15-49 in the 5 years before the survey, $31.7 \%$ of mothers were of age $<20$ years, $51.2 \%$ mothers were of age $20-24$ years, and $17.1 \%$ of mothers were of age $>24$ years. In our study, the mean age of all mothers was $28.25 \pm 4.51$ ranging from 18-41 years.

A study from Pakistan showed a significant difference in perinatal outcomes and morbidity in ANC users and non-users. This study also showed that the ANC non-users had a much higher percentage (49\%) of anemia as compared to ANC users (29\%). ${ }^{11}$ Our study was consistent with this study. Anemia in pregnant women is reported to be associated with poor outcomes. ${ }^{17}$ Hypertension in Pregnancy is commonly reported in underdeveloped countries. ${ }^{18}$ Out of $30.1 \%$ of females in our study also reported having hypertension. However, its incidence is less in Pakistan compared to neighboring countries like India. ${ }^{19}$

Most women in Pakistan deliver by spontaneous vaginal delivery $(70 \%)$ followed by instrumental delivery $(20 \%){ }^{20}$ About $10-20 \%$ women deliver by caesarian section. ${ }^{21}$ We found that mothers with anemia mostly delivered by spontaneous vaginal delivery and more mothers with hypertension and diabetes had to undergo caesarian section.

It is well known that frequent antenatal visits prevent morbidity and mortality in the mother and child. ${ }^{22}$ We also found maternal morbidity and pregnancy-related complications to be significantly less ( $p$ value $\leq 0.001$ ) in booked mothers as compared to unbooked mothers. Frequency of anaemia was $20.3 \%$ in unbooked mothers whereas it was $3.5 \%$ in booked mothers. Hypertension was $40.7 \%$ in unbooked mothers whereas it was $4.9 \%$ in booked mothers. Diabetes mellitus was $6.5 \%$ in unbooked mothers whereas it was $0.9 \%$ in booked mothers. Out of $41 \%$ of unbooked mothers had comorbidities whereas $23.6 \%$ of booked mothers had comorbidities. About $24.8 \%$ of unbooked mothers had some complications of pregnancy whereas only $4.3 \%$ of booked mothers had complications of pregnancy.

In our study, out of total 2885 mothers who gave live births in three military hospitals, only one $(0.034 \%)$ mother died (who was unbooked) in hospital in Jhelum. The Maternal Mortality Ratio (MMR) was 34.66 per 100,000 live births. ${ }^{10}$

Research is needed for determining the reason for pregnant women not attending standard antenatal care of 4 ANC visits as recommended by the World Health Organization in 2002 in the Focused Approach on ANC (FANC) and minimal eight contacts during pregnancy set by WHO in 2016,23 in our hospitals where all services are free of cost for the entitled clientele. Research on interventions for improving the quality and components of antenatal care and their effects on maternal mortality and morbidity, and neonatal mortality and morbidity.

\section{ACKNOWLEDGEMENTS}

We are extremely grateful to our esteemed supervisor Brig Mahmood Ur Rahman (Retd), Prof of Community Medicine, HITEC Institute of Medical Sciences Taxila for his continuous supervision and kind guidance during this research. We extend our heartfelt gratitude to Prof Dr Shahzad Ali Khan, Head of Department of Public Health at Health Services Academy Islamabad for his valuable input and kind guidance at every stage of this project.

\section{CONCLUSION}

Women in our study population were not utilizing Antenatal care services appropriately, as only $12 \%$ were found to be booked. Anaemia, hypertension and diabetes were the most common comorbidities in expecting mothers. Unbooked mothers had more comorbidities and complications of pregnancy as compared to those who were booked for antenatal care. There was a statistically significant association between maternal comorbidity and maternal complications of pregnancy and booked and unbooked status of mothers ( $p$-value $<0.001)$. Utilization of antenatal care services is beneficial in the prevention of maternal morbidity and complications of pregnancy, and thus improving maternal health.

\section{Conflict of Interest: None.}

\section{Authors' Contribution}

RA: Conception, study design, literature review, collection, analysis and interpretation of data, results, discussion, NA: Planning, study design, drafting, discussion, FARM: Detailed literature review, drafting, discussion, writing, AT: Literature 
review, collection, analysis and interpretation of data, drafting, MW: Conception, literature review, collection of data.

\section{REFERENCES}

1. Pakistan Demographic Health Survey PDHS 2018, [Internet] Available at: http://catalog.ihsn.org/index.php/catalog/7970\# metadata-data_access, (Accessed on June 4, 2019.

2. United Nations Millennium Development Goals Report 2009, [Internet] Available at: https://www.un.org/millenniumgoals/ pdf/MDG_Report_2009_ENG.pdf (Accessed on June 4, 2019.

3. Sustainable Development Goals Knowledge Platform. UN. 2019, [Internet] Available at: https:/ / sustainabledevelopment.un.org/, (Accessed on June 4, 2019.)

4. Omer S. The social and cultural factors of maternal mortality in the context of three delays: the perspective of lady health Workers of South Punjab, Pakistan, [Internet] Available at: http://pu.edu.pk/images/journal/studies/PDF-FILES/ 11_v20_1_19.pdf (Accessed April 15, 2020).

5. Sheikh S, Qureshi RN, Raza F, Memon J, Ahmed I, Vidler M, et al. Self-reported maternal morbidity: Results from the community level interventions for pre-eclampsia (CLIP) baseline survey in Sindh, Pakistan. Pregnan Hypert 2019; 17(2): 113-120.

6. Khan A, Bashir Soofi S, Shujaat Zaidi SH, Habib A, Mtiaz H. Pakistan National Nutrition Survey, 2011 Zulfiqar A Bhutta.; 2011, [Internet] Available at: https://ecommons.aku.edu/. (Accessed April 15, 2020)

7. Noh JW, Kim Y mi, Lee LJ, Akram N, Shahid F. Factors associated with the use of antenatal care in Sindh province, Pakistan: A population-based study. PLoS One 2019; 14(4): e0213987.

8. Iqbal S, Ali I, Ekmekcioglu C. Increasing frequency of antenatal care visits may improve tetanus toxoid vaccination coverage in pregnant women in Pakistan. Hum Vaccin Immun 2020; 1(1): 1-4.

9. Bhutta ZA, Hafeez A, Rizvi A, Ali N, Khan A, Ahmad F, et al. Reproductive, maternal, newborn, and child health in Pakistan: Challenges and opportunities. Lancet 2013; 381(9884): 2207-2218.

10. Akbar R. Neonatal mortality and morbidity in booked and unbooked mothers in military hospitals (a comparative cross sectional study) [Thesis]. Rawalpindi, PK; AFPGMI: 2019.

11. Tabinda $Z$, Khan S. Perinatal outcomes in antenatal service users versus non-users in an insured population of Northern Punjab, Pakistan. Pakistan J Public Health. 2012, [Internet] Available at: https://www.cabdirect.org/cabdirect/abstract/20133095756. (Accessed April 15, 2020).
12. Khan N, Khan S, Khan N, Khan S. Factors affecting utilization of maternal and child health services: District Swat KPK Pakistan. Int J Inn Res Dev 2013; 2(8): 217-227.

13. Agha $\mathrm{S}$, Tappis $\mathrm{H}$. The timing of antenatal care initiation and the content of care in Sindh, Pakistan. BMC Pregnancy Childbirth. 2016; 16(1): 1-5.

14. Asim M, Malik N, Siddiqui S, Nawaz W, Ali F. Antenatal health care; a literature review of antenatal and postnatal health care utilization in Pakistan. Prof Med J 2017; 24(4): 495-499.

15. Sarfraz M, Tariq S, Hamid S, Iqbal N. Social and societal barriers in utilization of maternal health care services in rural Punjab, Pakistan. J Ayub Med Coll Abbottabad 2015; 27(4): 843849.

16. Nishtar S. Gateway Health Indicators of Pakistan-Gateway Paper II. Heartfile. 2007, [Internet] Availabe at: http://www.heartfile. org/pdf/GWP-II.pdf (Accessed July 9, 2020)

17. Mahmood T, Rehman AU, Tserenpil G, Siddiqui F, Ahmed M, Siraj F, et al. The association between iron-deficiency anemia and adverse pregnancy outcomes:a retrospective report from Pakistan. Cureus 2019; 11(10): 1-4.

18. Vivian Ukah U, Payne B, Lee T, Magee LA, Von Dadelszen P. External Validation of the fullPIERS model for predicting adverse maternal outcomes in pregnancy hypertension in lowand midd-le-income countries. Hypert 2017; 69(4): 705-711.

19. Magee LA, Sharma S, Nathan HL, Adetoro OO, Bellad MB, Goudar $S$, et al. The incidence of pregnancy hypertension in India, Pakistan, Mozambique, and Nigeria: A prospective population-level analysis. PLoS Med 2019; 16(4): e1002783.

20. Samad A. common modes of delivery among women with pregnancy exceeding beyond 42 Weeks. Vol 33.; 2017, [Internet] Available at: http://pjs.com.pk/journal_pdfs/jul-sep17/216.pdf. (Accessed April 15, 2020).

21. Abbas F, Amir Ud Din R, Sadiq M. Prevalence and determinants of caesarean delivery in Punjab, Pakistan. East Mediterr Health J 2019; 24(11): 1058-1065.

22. Godoy A, Mendoza D, Campos J, Escobedo L. Putting pregnancy track in hands of women to try to reduce maternal-fetal morbidity and mortality, [Internet] Available at: pdfs.Semanticscholar.org. 2019. (Accessed July 9, 2020)

23. WHO. WHO Recommendations on antenatal care for a positive pregnancy experience; 2016, [Internet] Available at: https:// apps.who.int/iris/bitstream/handle/10665/250796/9789241549 912-eng.pdf (Accessed July 9, 2020) 